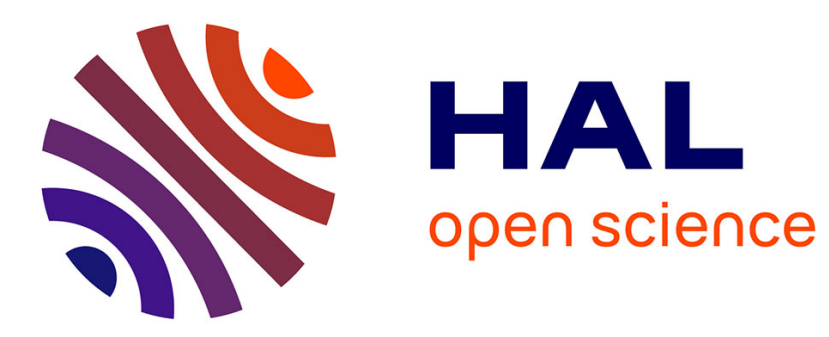

\title{
Towards a dynamic theory of intentions
}

\author{
Elisabeth Pacherie
}

\section{To cite this version:}

Elisabeth Pacherie. Towards a dynamic theory of intentions. S. Pockett, W.P. Banks \& S. Gallagher. Does Consciousness Cause Behavior? An Investigation of the Nature of Volition, MIT Press, pp.145167, 2006. ijn_00353954

\section{HAL Id: ijn_00353954 https://hal.science/ijn_00353954}

Submitted on 17 Jan 2009

HAL is a multi-disciplinary open access archive for the deposit and dissemination of scientific research documents, whether they are published or not. The documents may come from teaching and research institutions in France or abroad, or from public or private research centers.
L'archive ouverte pluridisciplinaire HAL, est destinée au dépôt et à la diffusion de documents scientifiques de niveau recherche, publiés ou non, émanant des établissements d'enseignement et de recherche français ou étrangers, des laboratoires publics ou privés. 
In S. Pockett, W.P. Banks \& S. Gallagher (eds) Does Consciousness Cause Behavior? An Investigation of the Nature of Volition. Cambridge, MA: MIT Press, 2006, pp. 145-167.

\title{
TOWARDS A DYNAMIC THEORY OF INTENTIONS
}

\author{
Elisabeth Pacherie \\ Institut Jean Nicod \\ CNRS-EHESS-ENS, Paris \\ pacherie@ehess.fr
}

\section{Introduction}

In this paper, I shall offer a sketch of a dynamic theory of intentions. I shall argue that several categories or forms of intentions should be distinguished based on their different (and complementary) functional roles and on the different contents or types of contents they involve. I shall further argue that an adequate account of the distinctive nature of actions and of their various grades of intentionality depends on a large part on a proper understanding of the dynamic transitions among these different forms of intentions. I also hope to show that one further benefit of this approach is to open the way for a more perspicuous account of the phenomenology of action and of the role of conscious thought in the production of action.

I take as my point of departure the causal theory of action (CTA). CTA is the view that behavior qualifies as action just in case it has a certain sort of psychological cause or involves a certain sort of psychological causal process. In the last decades, CTA has gained wide currency. Yet, it covers a variety of theories with importantly different conceptions of what constitutes the requisite type of cause or causal process qualifying a piece of behavior as an action. Broadly speaking, CTA takes actions to be associated with sequences of causally related events and attempts to characterize them in terms of certain causal characteristics they have. Versions of CTA can take different forms depending on what they take the elements of the action-relevant causal sequence to be and on what part of the sequence they identify as the action.

The earlier belief-desire versions of CTA, made popular most notably by Davidson (1980, Essay 1) and Goldman (1970), held that what distinguishes an action from a mere happening is the nature of its causal antecedent, conceived as a complex of some of the agent's beliefs and desires. However, it soon appeared that simple belief/desire versions of the causal theory are both too narrow and too unconstrained. On the one hand, they do not deal with 'minimal' actions, those that are performed routinely, automatically, impulsively or unthinkingly. On the other hand, 
they are unable to exclude aberrant manners of causation, when specifying the causal connection that must hold between the antecedent mental event and the resultant behavior for the latter to qualify as an (intentional) action.

Belief/desire versions of CTA are also largely incomplete. They account at best for how an action is initiated, but not for how it is guided, controlled and monitored until completion. They provide no analysis of the role of the bodily movements that ultimately account for the success or failure of an intended action. They say next to nothing about the phenomenology of action and what they do say does not seem right. On their accounting, the phenomenology of passive and active bodily movements could be exactly the same, which implies that an agent would know that she is performing an action not in virtue of her immediate awareness that she is moving, but only because she knows what the antecedent conditions causing her behavior are.

In order to overcome some of these difficulties and shortcomings, many philosophers have found it necessary to introduce a conception of intentions as distinctive, sui generis, mental states, with their own complex and distinctive functional role that warrants considering them as an irreducible kind of psychological state on a par with beliefs and desires. Thus, Bratman (1987) stresses three functions of intentions. First, intentions are terminators of practical reasoning in the sense that once we have formed an intention to $A$, we will not normally continue to deliberate whether to $A$ or not; in the absence of relevant new information, the intention will resist reconsideration. Second, intentions are also prompters of practical reasoning, where practical reasoning is about means of $A$-ing. This function of intentions thus involves devising specific plans for $A$-ing. Third, intentions also have a coordinative function and serve to coordinate the activities of the agent over time and to coordinate them with the activities of other agents.

Other philosophers (Brand, 1984; Mele, 1992) have pointed out further functions of intentions. They argue that intentions are motivators of actions and that their role as motivators is not just to trigger or initiate the intended action (initiating function) but also to sustain it until completion (sustaining function). Intentions have also been assigned a guiding function in the production of an action. The cognitive component of an intention to $A$ incorporates a plan for $A$-ing, a representation or set of representations specifying the goal of the action and how it is to be arrived at. It is this component of the intention that is relevant to its guiding function. Finally, intentions have also been assigned a monitoring function, involving a capacity to detect progress toward the goal and to detect, and correct for, deviations from the course of action as laid out in the guiding representation. 
The first three functions of intentions - their roles as terminators of practical reasoning about ends, as prompters of practical reasoning about means and as coordinators - are typically played in the period between initial formation of the intention and the initiation of the action. By contrast, the last four functions (initiating, sustaining, guiding and monitoring) are played in the period between the initiation of the action and its completion. Let me call the first set of functions practical-reasoning functions for short and the second set executive functions.

Attention to these differences has led a number of philosophers to develop dual-intention theories of action, that is theories that distinguish between two types of intentions. For instance, Searle (1983) distinguishes between prior intentions and intentions-in-action, Bratman (1987) between future-directed and present-directed intentions, Brand (1984) between prospective and immediate intentions, Bach (1978) between intentions and executive representations, and Mele (1992) between distal and proximal intentions. ${ }^{1}$

My own stance is that all seven functions are proper functions of intentions. I also think that at least two levels of guiding and monitoring of actions must be distinguished and that taking into account this distinction of levels is important in order to make sense of certain intuitive differences between intentional actions of varying grades. Furthermore, although important, a characterization of intentions uniquely in terms of their different functions remains insufficient. One must also take into account the different types of content intentions may have, their dynamics, temporal scales and explanatory roles.

This leads me to draw a more complex picture of the situation. In the next sections, I will try to motivate a threefold distinction among categories or levels of intentions: future-directed intentions, present-directed intentions, and motor intentions (F-intentions, P-intentions and $\mathrm{M}$ intentions for short). I shall also distinguish between two levels of dynamics in the unfolding of intentions: the local dynamics specific to each level of intention and the global dynamics involved in the transition from one level to the next. It is also useful to distinguish for each type of intention two phases of its internal dynamics: the upstream dynamics that culminates in the formation of the intention and the downstream dynamics manifested once the intention has been formed. I have tried to show elsewhere (Pacherie, 2003) how certain central difficulties and shortcomings of the more traditional versions of the causal theory may be overcome in this dynamic framework. Here I will focus on the phenomenology of action and on the role of conscious thought in the generation and control of action.

${ }^{1}$ For a more detailed analysis of the difficulties and shortcomings of the belief/desire versions of CTA and for an evaluation of some of the proposals made by dual-intention theorists, see Pacherie, 2000; 2003. 


\section{Future-directed intentions (F-intentions)}

Bratman stressed three functions of F-intentions, as terminators of practical reasoning about ends, prompters of practical reasoning about means and plans, and intra- and interpersonal coordinators. The upstream dynamics of F-intentions - the dynamics of decision-making that leads to the formation of an intention - are associated with the first of these three functions. Practical reasoning has been described by Davidson as a two-step process of evaluation of alternative courses of action. The first step consists in weighting possible alternative actions and reasons for and against each, and forming a judgement that, all things considered, some course of action is the best. The second step in the process consists in moving from this prima facie judgement to an unconditional or all-out judgement that this action is the best simpliciter. With this move we reach the end-point of the upstream dynamics: to form an all-out judgement is to form an intention to act.

The downstream dynamics of F-intentions is linked to their functions as prompters of practical reasoning about means and as intra- and interpersonal coordinators. This reasoning must be internally, externally, and globally consistent. All the intentions that are the building blocks of an action plan must be mutually consistent (internal consistency). The plan as a whole should be consistent with the agent's beliefs about the world (external consistency). Finally the plan must take into account the wider framework of activities and projects in which the agent is also involved and be coordinated with them in a more global plan (global consistency).

The dynamics of F-intentions, although not completely context-free, are not strongly dependent on the particular situation in which the agent finds himself when he forms the F-intention or reasons from it. I can form a F-intention to act an hour from now, next week, two years from now or once I retire from work. This temporal flexibility makes it possible for an agent to form a Fintention to perform an action of a given type even though his present situation is not such as to allow its immediate performance. A F-intention is therefore in principle detachable from the agent's current situation and is indeed commonly detached from it.

The rationality constraints that bear on F-intentions both at the stage of intention-formation and at the stage of planning and coordination require the presence of a network of inferential relations among intentions, beliefs, and desires. Concepts are the inferentially relevant constituents of intentional states. Their sharing a common conceptual representational format is what makes possible a form of global consistency, at the personal level, of our desires, beliefs, intentions and other prepositional attitudes. If we accept this common view, what follows is that 
for F-intentions to satisfy the rationality constraints they are subject to, they must have conceptual content.

In a nutshell then, the content of F-intentions is both conceptual and descriptive; it specifies a type of action rather than a token of that type. Because many aspects of an intended action will depend on unpredictable features of the situation in which it is eventually carried out, the description of the type of action leaves indeterminate many aspects of the action. A F-intention therefore always presupposes some measure of faith on the part of the agent, in the sense that the agent must trust herself at least implicitly to be able, once the time to act comes, to adjust her action plan to the situation at hand.

\section{Present-directed intentions (P-intentions)}

Philosophers who draw a distinction between future-directed intentions and present-directed intentions typically assign four functions to the latter: they trigger or initiate the intended action (initiating function), they sustain it until completion (sustaining function), they guide its unfolding (guiding function) and monitor its effects (monitoring function). We may call the first two functions motivational or volitional functions and the latter two control functions. Although there seems to be some consensus as to what the initiating and sustaining functions amount to, the situation is much less clear where the guiding and monitoring or control functions are concerned. My impression is that the disagreements among philosophers on these issues stem in a large part from the fact that they do not always distinguish clearly between two levels of guidance and monitoring. I will defend the view that higher-level guidance and monitoring are indeed functions of $\mathrm{P}$-intentions and are therefore subject to strong rationality constraints, whereas lower-level guiding and monitoring functions should properly be assigned to $\mathrm{M}$-intentions.

As we did with F-intentions, we can distinguish two stages in the dynamics of $\mathrm{P}$-intentions. Their upstream dynamics are concerned with the transformation of a F-intention into an intention to start acting now. The downstream dynamics concerns the period that goes from the initiation of the action up to its completion?2.

A P-intention often inherits an action plan from a F-intention. Its task is then to anchor this plan in the situation of action. The temporal anchoring, the decision to start acting now is but one aspect of this process. Once the agent has established a perceptual information-link to the situation of action, she must insure that the action plan is implemented in that situation. This means that she must effect a transformation of the purely descriptive contents of the action plan inherited from the F-intention into indexical contents anchored on the situation. When I decide to

2 Note that here by completion I simply mean the end of the action process, whether the action is successful or not. 
now act on my F-intention to go to the hairdresser, I must think about taking this bus, getting off at that stop, walking down that street to the hairdressing salon, pushing this door to enter the salon, and so on. As I do this I am anchoring my plan in the situation, making it more specific. When I formed the F-intention to go to the hairdresser a few days ago, I did not necessarily know where I would be when the time to act would come and which bus line would be most convenient. Only now, in the situation of action, can the 'getting there' element of the action plan can be specified in a detailed way.

Another essential function of P-intentions is to ensure the rational control of the ongoing action. It is important to emphasize that what is specifically at stake here is the rational control of the action, since, as we shall see, motor intentions also have a control function although of a different kind.

What should we understand rational control to be? Here, I will follow Buekens, Maesen and Vanmechelen (2001) 3 who describe rational control as taking two forms, the second of which is often ignored in the literature. The first type of rational control they describe is what they call 'tracking control'. Tracking control enables an agent to keep track of her way of accomplishing an action and to adjust what she does to maximize her chances of success. The second type of rational control is what they call 'collateral control', i.e. control of the side effects of accomplishing an action. The agent may notice undesirable side effects of her ongoing action and correct her way of accomplishing it in order to minimize them, or even abort the action. For instance, if I intended to surprise a friend by, for once, being on time at our appointment but find that the traffic is such that I could only do it by speeding madly in the crowded streets, I might renounce trying to arrive on time and leave that surprise for some other occasion. Both types of control are rational insofar as what the agent does in both cases is connect her indexical conception of her ongoing action to general principles of means-end reasoning, to her desires, values, general policies and rules of conduct. The agent exercises rational control over her action insofar as (1) she is in a position to judge whether or not his way of accomplishing her action is likely to lead to success and adjusts it so as to maximize her chances of success (tracking control) and (2) she is also in a position to judge whether or not it brings about undesirable side-effects and corrects it accordingly (collateral control). P-intentions, are thus,

\footnotetext{
3 Buekens, Maesen and Vanmechelen (2001) are to my knowledge the only authors who explicitly argue in favor of distinguishing three categories of intentions. They call them future-directed intentions, actioninitiating intentions and action-sustaining intentions respectively. However, their typology differs from the typology presented here. Their action-initiating intention corresponds to the upstream phase of the dynamics of $P$-intention and their action-sustaining intention to its downstream phase. Another difference between their scheme and mine is that they make no room for motor intentions. They are also perfectly explicit that they are concerned with personal-level phenomena and that both action-initiating intentions and action-sustaining intentions present the action to the agent via observation and not experience. These authors defend two very interesting claims to which I fully subscribe. The first is that the content of 'action-sustaining intentions' is essentially indexical and action-dependent; the second is that the control these intentions have over the action is concerned not just with the way in which the intended goal is accomplished but also with the side-effects generated by this way of accomplishing this goal.
} 
like F-intentions, subject to strong rationality constraints. Unlike F-intentions, however, Pintentions don't have much temporal flexibility. Rather, insofar as a P-intention is tied to a corresponding ongoing action and gets deployed concurrently with it, it is subject to severe temporal constraints.

These temporal constraints are of two kinds: cognitive and action-related. Firstly, P-intentions are responsible for high-level forms of guidance and monitoring - they are concerned with aspects of the situation of action and of the activity of the agent that are both consciously perceived and conceptualized. Therefore the time scale of P-intentions is the time scale of conscious perception and rational thought. Their temporal grain is a function of the minimal time threshold required for conscious rational thought. Second, their temporality is also constrained by what we may call the tempo of the action. This is literally the case when, say, one is playing a piece of music on the piano and must respect the tempo and rhythm of the piece. It is also the case in many other kinds of actions. In a game of tennis, one is allowed very little time to decide on how to return a serve. A slow tempo offers better conditions for online rational guidance and control of the action, since the agent has more time to decide on adjustments or to consider and evaluate possible side effects. In contrast, when the tempo is extremely fast, possibilities for online rational control may be very limited. In a nutshell, for a P-intention to play its role of guidance and control, it must be the case that the tempo of the action is not faster then the tempo of conscious rational thought; or, more accurately, it is only on those aspects of an action the tempo of which does not exceed the tempo of conscious rational thought that P-intentions can have rational control.

\section{Motor intentions (M-intentions)}

I claimed in the previous section that it was important to distinguish between two levels of action: guidance and control. P-intentions are responsible for high-level forms of guidance and monitoring, applying to aspects of the situation of action and of the activity of the agent that are both consciously perceived and conceptualized. However, work in the cognitive neuroscience of action shows that there also exist levels of guidance and control of an ongoing action that are much finer-grained, responsible for the precision of the action and the smoothness of its execution. $\mathrm{P}$-intentions and $\mathrm{M}$-intentions are both responsible for the online control of action, but whereas the time scale at which the former operate is the time scale of the consciously experienced present, the latter's time scale is that of a neurological micro-present, which only partially overlaps the conscious present.

We have seen that the move from F-intention to corresponding P-intention involves a transformation of a descriptive, conceptual content into a perceptual, indexical content. The role 
of a M-intention is to effect a further transformation of perceptual into sensory-motor information. $\mathrm{M}$-intentions therefore involve what neuroscientists call motor representations.

I will not here attempt to review the already considerable and fast growing empirical literature on motor representations ${ }^{4}$. A brief description of the main characteristics of these representations will suffice. It is now generally agreed that there exist two visual systems, dedicated respectively to vision for action and for semantical perception (i.e. the identification and recognition of objects and scenes) $)^{5}$. The vision for action system extracts from visual stimuli information about the properties of objects and situations that is relevant to action, and uses this to build motor representations used in effecting rapid visuo-motor transformations. The motor representations produced by this system have three important characteristics. First, the attributes of objects and situations are represented in a format useful for the immediate selection of appropriate motor patterns. For instance, if one wants to grab an object, its spatial position will be represented in terms of the movements needed to reach for it and its shape and size in terms of the type of hand grip it affords. Second, these representations of the movements to be effected reflect an implicit knowledge of biomechanical constraints and the kinematic and dynamic rules governing the motor system. Thus, for instance, the movements of the effectors will be programmed so as to avoid awkward or uncomfortable hand positions and to minimize the time spent in extreme joint angles. Third, a motor representation normally codes for transitive movements, where the goal of the action determines the global organization of the motor sequence. For instance, the type of grip chosen for a given object is a function not just of its intrinsic characteristics (its shape and size) but also of the subsequent use one wants to make of it. The same cup will be seized in different ways depending on whether one wants to carry it to one's lips or to put it upside down. A given situation usually affords more than just one possibility for action and can therefore be pragmatically organized in many different ways. Recent work suggests that the affordances of an object or situation are automatically detected even in the absence of any intention to act. These affordances automatically prepotentiate corresponding motor programs (Tucker \& Ellis, 1998; Grèzes \& Decety, 2002).

One can therefore also distinguish two moments in the dynamics of M-intentions. The upstream dynamics is the process that leads to the selection of one among the typically several prepotentialized motor programs. When a M-intention is governed by a P-intention and inherits its goal from it, the presence of the goal tends to increase the salience of one of these possible pragmatic organizations of the situation and thus allow for the selection of the corresponding motor program. But it can also be the case that M-intentions are formed in the absence of a P-

\footnotetext{
4 See Jeannerod (1997) for a review and synthesis of recent work in the cognitive neuroscience of action. 5 This of course does not mean that the two systems do not interact in some ways. See Milner \& Goodale (1995), Rossetti \& Revonsuo (2000) and Jacob \& Jeannerod (2003) for discussions of these interactions.
} 
intention. In such cases, the upstream dynamics work in a different way. According to the model proposed by Shallice (1988) there is then a competition among motor programs, with the program showing the strongest activation being triggered as a result of a process he calls contention scheduling.

The guidance and monitoring functions of M-intentions are exercised as part of its downstream dynamics. According to the neuro-computational models of action control developed in the last two decades, the motor system makes use of internal models of action in order to simulate the agent's behavior and its sensory consequences ${ }^{6}$. The internal models that concern us here are of two kinds: inverse models and forward or predictive models. Inverse models capture the relationships between intended sensory consequences and the motor commands yielding those consequences. They are computational systems, which take as their inputs representations of (a) the current state of the organism (b) the current state of its environment and (c) the desired state and yield as their outputs motor commands for achieving the desired state. By contrast, the task of predictive or forward models is to predict the sensory consequences of motor commands. Although strictly speaking it is an oversimplification ${ }^{7}$, one might say that inverse models have a guiding function - their job is to specify the movements to be performed in order to achieve the intended goal - and forward models have a monitoring function - their job is to anticipate the sensory consequences of the movements and adjust them so that they yield the desired effect. In most sensory-motor loops there are large delays between the execution of a motor command and the perception of its sensory consequences, and these temporal delays can result in instability when trying to make rapid movements and a certain jerkiness and imprecision in the action. It is hypothesized that predictive models allow the system to compute the expected sensory consequences in advance of external feedback and thus make faster corrections of the movements, preventing instability.

P-intentions and F-intentions must maintain the internal, external and global consistency of an action plan are therefore subject to strong rationality constraints. In contrast, M-intentions are not subject to these constraints. This is a consequence of the fact that the motor system exhibits some of the features considered by Fodor (1983) as characteristic of modular systems. It is informationally encapsulated, with only limited access to information from other cognitive systems or subsystems. To take a well-known illustration, when you move your eye using your eye muscles, the sensory consequences of this movement are anticipated and the displacement

6 See, for instance, Wolpert (1997), Jordan \& Wolpert (1999) and Wolpert \& Ghahramani (2000) for a review of neurocomputational approaches to motor control.

7 This is an oversimplification insofar as there exist complex internal loops between inverse models and predictive models. In practice, it is therefore difficult, if not impossible, to draw the line between guidance and control. 
of the image on the retina is not interpreted as a change in the world; but when you move your eye by gently pressing on the eyelid with the finger, the world seems to move. When we press on our eyeball with our finger, we are well aware that it is our eye that is moving and not the world, but the forward model in charge of predicting the sensory consequences of our motor performances has no access to that information. Similarly, the fact that the motor system does not seem to be sensitive to certain perceptual illusions suggests that the inverse models that operate online do not typically have access to conscious perceptual representations (nonveridical in the case of illusions) constructed by the vision for perception or semantical visual system ${ }^{8}$.

Obviously the motor system cannot be fully encapsulated. If it were, it would be impossible to explain how a P-intention can trigger motor behavior, or that the way we grasp an object depends not just on immediate sensory affordances but also on our prior knowledge of the function of this object. But it is likely that the motor system has only limited access to the beliefdesire system and that this access is typically mediated by P-intentions. I can have mistaken beliefs about the pattern of muscular contractions involved in my raising my arm, but when I raise my arm the motor system does not exploit this belief to produce some weird gesticulation.

A second feature of the motor system is its limited cognitive penetrability. We have only a limited conscious access to the contents of our motor representations. The motor system does not seem to fall squarely on either side of the divide between the personal and the subpersonal. Some aspects of its operation are consciously accessible, others do not seem to be. Several studies (Jeannerod, 1994; Decety \& Michel, 1989; Decety et al. 1993; Decety et al., 1994) have shown that we are aware of selecting and controlling our actions and that we are capable of imagining ourselves acting. Moreover, the awareness we have of the movements we intend to perform is not based solely on the exploitation of sensory reafferences, because paralyzed subjects can have the experience of acting. However, other studies indicate that we are not aware of the precise details of the motor commands that are used to generate our actions, or of the way immediate sensory information is used for the fine-tuning of those commands (Fourneret et Jeannerod, 1998). For instance, several pointing experiments (Goodale et al., 1986; Castiello et al., 1991) have shown that in a task where subjects have to point with their finger a target, they can do so accurately even on trials where the target is suddenly displaced by several degrees and they have to adjust their trajectories. Moreover, they can do so while remaining completely unaware both of the displacement of the target and of their own

\footnotetext{
8 Regarding this latter case, caution is required however, first because the interpretation of the various experiments reporting such data is still a matter of debate (Aglioti et al., 1995; Gentilucci et al., 1996; Haffenden \& Goodale, 1998; Jacob \& Jeannerod, 2003) and, second, because the experiments that have been conducted also suggest that when a delay is introduced between the sensory stimulation and the action, illusory perceptions can influence action.
} 
corrections. One series of experiments devised by Rossetti and his coworkers (Pisella et al., 1998) is especially instructive. In one condition, a green target was initially presented and subjects were requested to point at it at instructed rates. On some trials the visual target was altered at the time of movement onset. It could either jump to a new location, change color or both. Subjects were instructed to point to the new location when the target simply jumped, but to interrupt their ongoing movement when the target changed color or both changed color and jumped. The results showed that when the target changed both color and position in a time window of about 200-290 ms, the subjects would point at the displaced target instead of interrupting their ongoing movement. The very fast inflight movement corrections made by the visuo-motor system seem to escape conscious voluntary control. According to the explanatory scheme proposed here, this experiment may be interpreted as showing that M-intentions have a dynamics of their own, which is not entirely under the control of P-intentions.

These kinds of experiments also illustrate the fact that $\mathrm{P}$-intentions and $\mathrm{M}$-intentions operate at different time scales. The type of control exercised by P-intentions is, as we seen, both rational and conscious. Temporal constraints on conscious processes set a minimal temporal threshold for information to become consciously accessible. Rossetti et al.'s experiments illustrate the existence of at least a partial incompatibility between the temporal constraints the motor system must satisfy to perform smooth online corrections and adjustments of an action and the temporal constraints on conscious awareness.

\section{General dynamics of intentions}

I distinguished earlier between two levels of dynamics: the local or micro-level dynamics specific to each type of intention and the global or macro-level dynamics of the transition from Fintentions to $\mathrm{P}$-intentions and $\mathrm{M}$-intentions. Some characteristics of this macro-level dynamics can easily be inferred from what was said of the local dynamics of each type of intention. In particular, the global dynamics of the transition from F-intentions to P-intentions and $\mathrm{M}$ intentions involves a transformation of the contents of these respective intentions. We move from contents involving descriptive concepts, to contents involving demonstrative and indexical concepts and from there to sensori-motor contents. This transformation also involves a greater specification of the intended action. Many aspects of the action that where initially left indeterminate are specified at the level of the P-intention and get further specified at the level of the M-intention.

Yet, one may want to know what it is that insures the unity of the intentional cascade from Fintentions, to P-intentions and to M-intentions if their respective contents differ. In a nutshell, the answer is that what insures this unity is the fact that each intention inherits its goal from its predecessor in the cascade. However, such an answer may seem to raise a problem: if the mode of presentation (MP) of the goal differs from one level of intention to the next, in what 
sense can we talk of an identity of goal? Suppose my F-intention is to get rid of the armchair I inherited from my uncle. A conversion of this F-intention into a corresponding P-intention requires (among other things) a transformation of the purely descriptive MP of this target object into a perceptual MP. But one problem is that being inherited from one's uncle is not an observational property. At the level of the P-intention the target object of the action will have to be recaptured under a different MP, say for instance as the red armchair next to the fireplace. Similar problems will arise when moving from P-intentions to $\mathrm{M}$-intentions where goals are encoded in sensory-motor terms.

To ensure the unity of the intentional cascade, the transformation of the MPs of the action goal must be rule-governed. By a rule-governed transformation, I mean a transformation of MPs that exploits certain identities. More precisely, if we consider the transition from a F-intention to a Pintention - a transition that is subject to strong rationality constraints - identities should not just be exploited, they should be recognized as such by the agent. For instance, it is because I judge that the armchair I inherited from my uncle is the same object as the red armchair next to the fireplace that the unity of my F-intention to get rid of the armchair I inherited from my uncle with my P-intention to get rid of the red armchair I visually perceive next to the fireplace is warranted. By contrast, when we consider the transition from P-intentions to M-intentions, it seems that certain identities are hardwired in the motor system and are as a result systematically exploited. For instance, in the Rossetti et al.'s experiment discussed earlier, the target to which the subject should point is identified both by its color and by its position. Information on color is processed by the system for semantical perception but is not directly accessible by the visuo-motor system. Yet, this latter system can directly process information on position. When the subject is instructed to point to the green target, the transition from the P-intention to the M-intention exploits the following identity: 'the green target $=$ the target located at p'. In other words, the Pintention to point to the green target unless it changes color gets transformed into a M-intention to point to the target located at $p$. At the motor level, the movement will be controlled by the position of the target and not its color and it will be automatically adjusted in response to a change of position.

What I have said so far on the dynamics of the three types of intentions in no way implies that all actions require the presence of the entire intentional cascade. Some decisions to act are made on the fly and do not warrant a distinction between a F-intention and a P-intention. If a colleague knocks at my office door around noon and asks me if I want to join him for lunch now, I may just say yes and follow him to the cafeteria. I may possibly deliberate for a minute: am I really hungry? Is the thing I am doing now really so urgent that I should get over with it before going for lunch? But once I have made up my mind, I immediately start acting. In such cases, there is not really room for a distinction between a F-intention and a P-intention. 
The existence of automatic, spontaneous or routine actions suggests that it is not even always necessary that I form a P-intention in order to start acting. When, while trying to make sense of some convoluted sentence I am reading, I automatically reach for my pack of cigarettes, my action seems to be triggered by the affordances offered by the pack of cigarette and need not be controlled by a P-intention. It is interesting to note that even when a given action happens to be controlled by a P-intention, it is not necessarily this P-intention that triggered the action. If I am a heavy smoker and am completely absorbed by some philosophical argument I am trying to unravel, I can take a cigarette and light it without even noticing what I am doing. If, while this action unfolds, I become aware of what I am doing, I may decide whether or not I should go on with the action. If I do decide to carry on, the action that had been initially triggered by a Mintention is now also controlled by a P-intention. Finally, it should also be noted that P-intentions can have varying degrees of control on the unfolding of an action. Well-practiced actions require little online control by P-intentions. In contrast, novel or difficult actions are typically much more closely controlled by P-intentions.

\section{Conscious agency}

I now turn to the problems of conscious agency and the bearing the dynamic theory of intentions presented here may have on them. Let me start by distinguishing three issues. The first issue is concerned with the phenomenology of action, understood as the experience of acting one may have at the time one is acting. The second issue concerns mental causation, i.e. the question whether or not mental states play a causal role in the production of actions. The third issue concerns the phenomenology of mental causation, or to use Wegner's phrase, the experience of the conscious will, conceived as the experience one may have that one's actions are caused and controlled by one's conscious states. The latter two issues are often confused, with the unfortunate consequence that evidence that experiences of mental causation are sometimes non-veridical is taken as evidence that the very notion of mental causation is mistaken. Similarly, the phenomenology of action in the sense outlined above should not be confused with the phenomenology of mental causation. One's awareness that one is acting is not the same thing as one's awareness that one's action is caused by one's conscious mental states. The experience of acting may well be an ingredient in the experience of mental causation but it is not all there is to it. I will first try to provide an analysis of the experience of acting. I will then turn to the issue of mental causation and argue that Libet's experiments provide no conclusive reasons to think that mental causation is generally illusory. Finally, I will move on to the phenomenology of mental causation and argue that Wegner's experiments are similarly inconclusive in ruling out actual mental causation.

As mentioned in section 1, one objection addressed to the earlier belief/desire versions of CTA was that they failed to account for the phenomenology of action. Their central claim is that what distinguishes actions from other events is the nature of their mental antecedents conceived as complexes of beliefs and desires. An agent would know that she is performing an action not in virtue of her immediate awareness that she is moving, but because she knows what the 
antecedent conditions causing her behavior are. Such an inferential approach seems unable to account for the specificity and the immediacy of the phenomenology of bodily action. One reason the phenomenology of action may have been neglected is that it is much less rich and salient than the phenomenology of perception. Typically, when we are acting, our attentional focus in on the outside world we are acting on rather than on the acting self. Our awareness of our active bodily involvement is only marginal. Typically also, the representational content of the experience of acting is relatively unspecific and elusive.

In the model proposed here three types of intentions are distinguished. F-intentions, insofar as they are temporally separated from the action, make no direct contribution to the experience of acting, although they may play an indirect role and contribute to a sense of personal continuity and to a temporally extended sense of one's agency. By contrast, P-intentions and M-intentions are both simultaneous with the action that they guide and control and hence are both immediately relevant to the phenomenology of agency. Here I follow Wakefield and Dreyfus (1991) and distinguish between knowing what we are doing and knowing that we are acting. As these authors point out: 'Although at certain times during an action we may not know what we are doing, we do always seem to know during an action that we are acting, at least in the sense that we experience ourselves as acting rather than as being passively moved about' (1991: 268). One may further distinguish between knowing what we are doing in the sense of being aware of the goal of our action (and its general form), and knowing it in the sense of being aware of our specific manner of bringing about this desired result. In the framework proposed here, this distinction between three aspects of the experience of acting - which may be termed thatexperience, what-experience and how-experience - may be accounted for as follows. On the one hand, it is P-intentions, through their role of rational and perceptual guidance and monitoring of the ongoing action that are mainly responsible for what-experience. What-experience, that is, is awareness of the content of P-intentions. On the other hand, $\mathrm{M}$-intentions are responsible both for the most basic aspect of action phenomenology, that-experience, and for the most specific form it can take, how-experience. These two forms of the experience of acting nevertheless depend on rather different mechanisms.

As we have seen, motor control involves mechanisms of action anticipation and correction. According to recent neurocomputational models of motor control, motor control exploits internal models of action used to predict the effects of motor commands as well as comparators that detect mismatches between predicted effects, desired effects and actual effects in order to make appropriate corrections. Although, these mechanisms largely operate at the subpersonal level, in the sense that the representations they process are typically unavailable to consciousness, they may nevertheless underlie the experience of acting in its most basic form. In other words, our awareness that we are acting, the sense of bodily implication we experience may result from the detection by the comparison mechanisms used in motor control of a coherent sensory-motor flow. It is important to note that on this view, the basic experience that one is acting need not involve conscious access to the contents of the motor and sensory representations used for the control of the ongoing action. That is why, as Wakefield and Dreyfus remark, we may experience ourselves as acting without knowing what it is exactly we 
are doing. This is also why the representational content of the experience of acting may appear so thin. This is especially so when one is engaged in what I termed 'minimal' actions, actions that are performed routinely, automatically, impulsively or unthinkingly. These actions unfold with little or no conscious control by $\mathrm{P}$-intentions. Their phenomenology may therefore involve nothing more than the faint phenomenal echo arising from coherent sensory-motor flow.

In contrast, our awareness of the specific form our bodily implication in action takes - the exact trajectory of our arm, the precise way we are shaping our hand, say - requires a conscious access to the content of at least some of our current sensory-motor representations. It therefore requires that these normally unconscious representations be transformed into conscious ones. As Jeannerod (1994) points out, these representations are usually too short-lived to become accessible to consciousness. During execution, they are normally cancelled out as soon as the corresponding movements have been performed. Converting them into conscious representations therefore requires that they be kept in short-term memory long enough to become available to consciousness. This can happen when the action is blocked, delayed and, to some degree, also through top-down attentional amplification.

In a series of experiments, Jeannerod and co-workers (Fourneret and Jeannerod, 1998; Slachewsky et al., 2001) investigated subjects' awareness of their movements. Subjects were instructed to move a stylus with their unseen hand to a visual target: only the trajectory of the stylus was visible as a line on a computer screen, superimposed on the hand movement. A directional bias (to the right or to the left) was introduced electronically, such that the visible trajectory no longer corresponded to that of the hand, and the bias was increased from trial to trial. In order to reach the target, the hand-held stylus had to be moved in a direction opposite to the bias. In other words, although the line on the computer screen appeared to be directed to the target location, the hand movement was directed in a different direction. At the end of each trial, subjects were asked in which direction they thought their hand had moved by indicating the line corresponding to their estimated direction on a chart presenting lines oriented in different directions.

These experiments revealed several important points. Subjects accurately corrected for the bias in tracing a line that appeared visually to be directed to the target. When the bias was small, this resulted from an automatic adjustment of their hand movements in a direction opposite to the bias. Subjects tended to ignore the veridical trajectory of their hand in making a conscious judgement about the direction of their hand. Instead, they adhered to the direction seen on the screen and based their report on visual cues, thus ignoring non-visual (e.g., motor and proprioceptive) cues. However, when the bias exceeded a mean value of about $14^{\circ}$, subjects changed strategy and began to use conscious monitoring of their hand movement to correct for the bias and to reach the target. The general idea suggested by this result is that it is only when the discrepancy between the seen trajectory and the felt trajectory becomes too large to be automatically corrected that subjects become aware of it and use conscious compensation strategies. Thus, the experience of acting may become vivid and be endowed with detailed 
representational content only when action errors occur that are large enough that they can't be automatically corrected. ${ }^{9}$

With respect to the issues of mental causation and its phenomenology, the main conclusion to be drawn from this discussion of the experience of doing is that such an experience need not and indeed should not be thought of as the experience of one's conscious mental states causing our actions. In its most basic form, exemplified in minimal actions, the experience of doing may reduce to the faint background buzz of that-experience: during the action, I am peripherally aware that I am acting rather than, say, being acted upon. Minimal actions may be experienced as doings without being experienced as purposive, intended or done for reasons. Something more than mere that-experience is required for an experience of mental causation. Whatexperience and how-experience may be further ingredients of the experience of mental causation by contributing a sense of purposiveness. But other factors may still be required as the experience of purposiveness may yet fail to qualify as an experience of mental causation.

But before I dwell further on this topic, let me get clear on what I think conscious mental causation is. First, the notion of a conscious state can be understood in at least two ways. We may want to say that a mental state is conscious if in virtue of being in that state, the creature whose state it is is conscious of the object, property or state of affairs the state represents or is about (first-order consciousness). Or we may want to say that a state is conscious if the creature whose state it is is conscious of being in that state, that is, has a representation of that state as a specific attitude of hers towards a certain content (second-order consciousness). Thus, an intention of mine will be conscious in the first of these two senses if I am conscious of the goal or means-goal relation the intention encodes (say, I raise my hand to catch the ball). For my intention to be conscious in the second sense, I must be aware of my intention as an intention of mine, where the state of awareness is distinct from the intention itself. I take it that the issue of mental causation is first and foremost concerned with whether or not conscious states understood in the first of these two senses are causally efficacious in the production of actions. Second, there is more to causation than the mere triggering of effects. Many other factors can contribute to shaping the effect triggered and there are no good reasons to deny them the status of causal factors. Similarly, effects are often not the result of a single causal event but of a chain of such events and there is usually no good reason to single out the first element of the chain as the cause. To claim that something can only qualify as a cause if it is some sort of prime mover unmoved is to cling to a doubtful tenet of Aristotelian metaphysics. Third, in a naturalistic, non dualistic framework, personal-level mental states are constituted or realized by complex physical states and a personal-level account of behavior must be backed up by a subpersonal explanation of how mental causation works. Subpersonal and personal-level explanations are pitched at different levels of generality and should therefore be seen as complementary rather than mutually exclusive.

$9^{9}$ For further discussion of these issues, see Jeannerod \& Pacherie (2004). 
For the notion of conscious mental causation to be vindicated, two conditions must be satisfied. First, it must be the case that conscious mental states and conscious intentions (in the first-order sense) can be elements in the causal chain of information processing that translates beliefs, desires, and goals into motor behavior and effects in the world. Second, it must be the case that the causal chains that include such conscious states as elements have distinctive functional properties. The first condition may be taken as a necessary condition for conscious mental causation. If conscious intentions were always post hoc reconstructions, they would be effects of actions rather than causes thereof. Note though that for a conscious intention to qualify as a causal contributor to an action it is not necessary that it be the very first element in the causal chain leading to the performance of the action. The second condition may be taken as a sufficient condition for the causal efficacy of conscious mental states. If it makes a difference whether or not a causal chain contains conscious mental states as elements, in particular if there are differences in the kinds of actions that can be the outcome of such chains or in the conditions in which such actions can be successfully performed, then it is fair to say that conscious mental states make a difference and are causally efficacious.

With respect to the first condition, although there may be cases where conscious intentions are retrospective illusions, nobody as ever offered convincing evidence for the claim that this is always the case. With respect to the second condition, there is plenty of evidence that automatic and non-automatic actions are not produced by the same mechanisms, that the performance of novel, difficult, complex or dangerous actions requires conscious guidance and monitoring 10 and that recovery from error in certain circumstances is not possible unless one switches from automatic to consciously-guided correction procedures. ${ }^{11}$ In particular, the fact that the same action may sometimes be performed automatically, sometimes consciously does not show that conscious states are causally idle. When the circumstances are favorable, the performance goes smoothly, and no breakdown occurs, one may indeed be under the impression that appealing to conscious mental states adds nothing of value to an explanation of why the action unfolds as it does and is successfully completed. To better see the causal import of conscious mental states, one should reason counterfactually and ask what would have happened had something gone wrong, had unexpected events occurred, the world or our body not behaved as predicted. The distinction I introduced earlier between the rational guidance and monitoring exerted at the level of conscious $\mathrm{P}$-intentions and the automatic guidance and monitoring

10 Here it may be useful to introduce Block's conceptual distinction between phenomenal consciousness and access-consciousness, where the former refers to the experiential properties of consciousness, for instance what differs between experiences of green and red, and the latter to its functional properties, access-conscious content being content made available to the global workspace and thus for use in reasoning, planning and verbal report. (Block, 1995). When one speaks of conscious guidance or monitoring, it is the notion of accessconsciousness that is, at least primarily, at stake. Block himself think that phenomenal consciousness and access-consicousness are dissociable, hence independent, thus leaving open the possibility that phenomenal consciousness is causally idle. Others, however, have argued that phenomenal consciousness provides a basis for wide availability to the cognitive system and is thus a precondition of access-consciousness (Kriegel, forthcoming).

11 See for instance Shallice (1988) and Jeannerod (1997). 
exerted at the level of unconscious M-intentions was meant to capture the important difference in the way automatic and non-automatic actions are produced. As I tried to make clear, each mode of guidance and monitoring has its specific strengths and limitations, linked to their respective representational formats, temporal dynamics, and to their modular or non modular character. Conscious guidance and monitoring in no way displaces the need for automatic motor guidance and monitoring. Indeed, because there are limits to how much of an action one can consciously monitor without interfering with its performance, conscious monitoring can be only partial and we must tacitly rely in large part on automatic control processes. Thus, conscious and unconscious processes necessarily coexist and play complementary roles in the control of non-automatic actions. They are not separate parallel streams but rather interact in complex ways, with control being passed up - for instance, when action errors are too large to be automatically corrected and control is passed to conscious processes - and down - as when we consciously focus on one aspect of an action and delegate control over other aspects to automatic motor processes.

Many people have seen in Libet's famous studies on the 'readiness potential' evidence in favor of a skeptical attitude towards conscious mental causation. Libet et al. (1983) asked subjects to move a hand at will and to note when they felt the urge to move by observing the position of a dot on a special clock. While the participants were doing this, the experimenters recorded their readiness potential, i.e. the brain activity linked to the preparation of movement. What they found was that the onset of the readiness potential (RP) predated the conscious awareness of the urge to move (W) by about $350 \mathrm{~ms}$., while the actual onset of movement measured in the muscles of the forearm occurred around $150 \mathrm{~ms}$ after conscious awareness. Libet (1985) and others have claimed that these results suggest that since the conscious awareness of the urge to move occurs much later than the onset of the brain activity linked to the preparation of movement occur, the conscious urge to move plays no causal role in the production of the intentional arm movement.

There are serious reasons to doubt that these results warrant such a conclusion. First, the conscious urge to move may lag behind the onset of brain activity but it still precedes the actual onset of movement. As I mentioned earlier, there is no good reason to think that only the initial element in a causal chain may genuinely qualify as a cause. A conscious mental state may play a causal role in the production of an action even though it doesn't trigger the whole causal process. One may add that the unconscious processes that precede conscious awareness are not themselves uncaused and that, by parity of reasoning, Libet should also deny that they initiate the action. Second, as Mele (2003) points out, it is unclear whether the readiness potential constitutes the neural substrate of intentions or decisions rather than of desires or urges. If the latter, it should indeed be expected to precede conscious intentions. Indeed, in a more recent experiment involving a task similar to Libet's, Haggard and Eimer (1999) showed that the readiness potential can be divided into two distinct phases, an early phase where the readiness potential is equally distributed over both hemispheres (RP) and a latter phase when it lateralizes, becoming larger contralateral to the hand that the subject will move. This second 
phase is known as the lateralized readiness potential (LRP). The first stage corresponds to a general preparation phase prior to movement selection, and a second with a specific preparation phase which generates the selected action. Their data suggest that while RP onset precedes the onset of conscious awareness, LRP onset coincides with conscious awareness and may constitute the neural correlate of the conscious decision to act. Third, Libet's analysis focuses on what I termed P-intentions and their relation to neural activity but it neglects F-intentions. Yet, his experiments involve F-intentions. The participants must at the very least have formed the Fintention to comply with the experimenter's instructions and to produce hand movements when they felt the urge. This F-intention has two uncommon features: it concerns a very simple hand action, of a kind one does not ordinarily need to plan for in advance, and, more strikingly, the initiation condition for the action takes a rather unusual form. Participants are asked to act at will or when they feel the urge, rather than when some external condition obtains. This could be achieved in at least two ways. The F-intention may cause it to be the case that the initiation condition is satisfied by generating an urge to move. Or, assuming such urges occur spontaneously on a more or less regular basis, the F-intention may direct attention toward them and initiate a process of attentional amplification. In either case, F-intentions are not causally inert. Haggard and Eimer's claim that the conscious intention to move one's hand coincides with the onset of LRP, the specific preparation phase which generates the selected action, is consistent with my claim that the content of a P-intention must be more specific than the content of a corresponding F-intention - it represents a specific act-token, e.g. that this hand move in such and such a way, rather than an action type. Finally, because the action the participants were requested to perform was such a simple and well-rehearsed element of their motor repertoire, it required little or no conscious planning and control. It is therefore not surprising that conscious awareness arises only $200 \mathrm{~ms}$ on average before actual movement onset. My bet is that for more complex or less familiar actions a longer time interval should elapse between onset of awareness and onset of movement.

Let me now turn to the third and last issue, the phenomenology of conscious mental causation, or as Wegner calls it, the experience of conscious will. Some of Wegner's experiments suggest that the experience of conscious will can be non-veridical. For instance, in his I-spy experiment (Wegner \& Wheatley, 1999), a participant and a confederate have joint control of a computer mouse that can be moved over any one of a number of pictures on a screen. When participants had been primed the name of an item on which the mouse landed, they showed an increased tendency to self-attribute the action of stopping on that object (when in fact the stop had been forced by the confederate). In other words, they experienced conscious will for an action they had not actually controlled. Some authors, including Wegner himself on occasion ${ }^{12}$, seem to think that the fact that the experience of conscious will can be non-veridical is evidence for the claim that conscious mental causation is an illusion. This inference appears less than

12 See, for instance, Wegner, 2002, p. 342, Wegner, 2003, p. 261. See also Libet (2004) and Pockett (2004). 
compelling. To show that the experience of willing is not always errorless is certainly not to show that it is always in error.

It has long been recognized that although we can be aware of the contents of our thoughts, we have little or no direct conscious access to the mental processes these thoughts are involved in. ${ }^{13}$ Mental processes, in other words, are not phenomenally transparent. Wegner may well be right that the experience of conscious will is typically not a direct phenomenal readout of our mental processes and must be theoretically mediated. In his view, the experience of consciously willing our actions seems to arise primarily when we believe our thoughts have caused our actions. For this to happen, "the thought should be consistent with the action, occur just before the action, and not be accompanied by other potential causes" (2003: 3) Tim Bayne (this volume) raises doubts as to whether, as Wegner's model suggests, a mere match between thought and action suffices to generate the experience of conscious will. Bayne suggests that it may further be required that one be aware of the prior state as one's own. It may also be required that one identifies this state as a state of intention. As I mentioned earlier, a state may be conscious in the sense that one is conscious of its content without being conscious in the sense that one is conscious of being in that state. While acting, one should normally be expected to attend to the world in which one is acting, rather than to one's state of intending. Intentions may therefore be conscious in the first sense, while not being conscious in the second. One's conscious intentions (in the first sense) may therefore cause an action without one having an experience of conscious will. One may simply have an experience of doing while performing the action caused by the conscious intention. Thus, conscious F-intentions or Pintentions may well play a role in the production of an action without this action giving rise to an experience of conscious will if the agent is focusing on the situation of action rather than on his or her mental states and thus is not conscious of these F-intentions and P-intentions as states of intention she is in.

Moreover, our second-order awareness of our first-order conscious states, understood as the awareness of one's attitude towards a certain content may well be inferentially mediated and fallible. We may be mistaken in identifying a first-order conscious state as a state of intention rather than, say, as a mere thought. For instance, as Bayne suggests, we may identify a prior thought as an intention because its content is consistent with an action performed in its wake. We can therefore have a non-veridical experience of conscious will, when a conscious thought that is not a conscious intention is mistaken for one. This seems to be what is happening in Wegner's I-spy experiment.

Yet, it is unsure that the participants in this experiment would have had an experience of conscious will, veridical or non-veridical, simply in virtue of a correspondence between their consciously experienced prior thought and the target action and of a misidentification of this prior thought as an intention. One further element that may be necessary is an experience of doing. As I argued earlier, this experience can be very unspecific and reduce to a that-experience. Of course, the veridicality of an experience of doing does not guarantee the veridicality of the 
experience of conscious will of which it may be a component. The participants in the I-spy experiment that were tricked into thinking that they were responsible for stopping the mouse cursor on a certain item were wrong about that but were at least right that they had been acting. Had they not been acting at all, it is unclear whether they have had an experience of conscious will. There are therefore several reasons why experiences of conscious will and actual mental causation may fail to coincide. Conscious intentions may be causally efficacious without giving rise to an experience of conscious will and an experience of conscious will may be present where conscious intentions are not causally involved. The dynamic theory of intentions I have sketched certainly leaves open both possibilities. Yet, as we have independent reasons to think that conscious intentions (in the first-order sense) are causally efficacious in the production of actions and no good reasons to think that our second-order awareness of intentions is always or most of the time the result of a misidentification of mere thoughts with actual intentions, we can, I think, remain confident that the experience of conscious will is a reliable indicator of actual mental causation.

13 See, e.g., Nisbett \& Wilson (1977). 


\section{References}

Aglioti, S., DeSouza, J. F. X. \& Goodale, M. A. 1995. Size-contrast illusions deceive the eye, but not the hand. Current Biology, 5: 679-685.

Bach, K. 1978. A Representational Theory of Action. Philosophical Studies, 34, 361-379.

Block, N. 1995. On a confusion about a function of consciousness. Behavioral and Brain Sciences, 18: 227-247.

Brand, M. 1984. Intending and acting. Cambridge, MA.: MIT Press.

Bratman, M. E. 1987. Intention, Plans, and Practical Reason. Cambridge, MA: Cambridge University Press.

Buekens, F, Maesen, K. \& Vanmechelen, X. 2001. Indexicaliteit en dynamische intenties. Algemeen Nederlands Tijdschrift voor Wijsbegeerte, 93: 165-180.

Castiello, U., Paulignan, Y. \& Jeannerod, M. 1991. Temporal dissociation of motor responses and subjective awareness. A study in normal subjects. Brain, 114: 2639-2655.

Davidson, D. 1980. Essays on Actions and Events. Oxford: Oxford University Press.

Decety, J., \& Michel, F. 1989. Comparative analysis of actual and mental movement times in two graphic tasks. Brain and Cognition, 11: 87-97.

Decety, J., Jeannerod, M., Durozard, D, \& Baverel, G. 1993. Central activation of autonomic effectors during mental simulation of motor actions. Journal of Physiology, 461: 549-563.

Decety, J., Perani, D., Jeannerod, M., Bettinardi, V., Tadary, B., Woods, R., Mazziotta, J. C., \& Fazio, F. 1994. Mapping motor representations with PET. Nature, 371: 600-602.

Fodor, J. A. 1983. The Modularity of Mind. Cambridge, Mass.: MIT Press.

Fourneret, P. \& Jeannerod, M. 1998. Limited conscious monitoring of motor performance in normal subjects. Neurospychologia, 36: 1133-1140.

Gentilucci, M., Chiefffi, S., Daprati, E., Saetti, M.C. \& Toni, I. 1996. Visual illusion and action. Neuropsychologia, 34: 369-376.

Goldman, A. 1970. A Theory of Human Action. Englewood Cliffs, NJ: Prentice-Hall.

Goodale, M.A., Pélisson, D. \& Prablanc, C. (1986) Large adjustments in visually guided reaching do not depend on vision of the hand or perception of target displacement. Nature, 320: 748-750.

Grèzes, J. \& Decety, J. 2002. Does visual perception afford action? Evidence from a neuroimaging study. Neuropsychologia, 40: 1597-1607.

Haffenden, A. M. \& Goodale, M. A. 1998. The effect of pictorial illusion on perception and prehension. Journal of Cognitive Neuroscience, 10: 122-136.

Haggard, P \& Eimer, M. 1999. On the relation between brain potentials and the awareness of voluntary movements. Experimental Brain Research, 126: 128-133.

Jacob, P. \& Jeannerod, M. 2003. Ways of Seeing, the Scope and Limits of Visual Cognition. Oxford: Oxford University Press. 
Jeannerod, M. \& Pacherie, E. 2004. Agency, Simulation and Self-identification. Mind \& Language, 19, 2: 113-146.

Jeannerod, M. 1994. The representing brain: neural correlates of motor intention and imagery.

Behavioral and Brain Sciences, 17: 187-246.

Jeannerod, M. 1997. The cognitive neuroscience of action. Oxford: Blackwell.

Jordan, M. I. \& Wolpert, D. M. 1999. Computational motor control. In M. Gazzaniga, (Ed.), The Cognitive Neurosciences. Cambridge, MA: MIT Press.

Kriegle, U. Forthcoming. The Concept of Consciousness in the Cognitive Sciences. In P. Thagard (ed.), Handbook of Philosophy of Psychology and Cognitive Science, Amsterdam: Elsevier.

Libet, B. 1985. Unconsicous cerebral initiative and the role of conscious will in voluntary action. Behavioral and Brain Sciences, 8: 529-566.

Libet, B. 2004. Mind Time. Cambridge, MA: Harvard University Press.

Libet, B., Gleason, C. A., Wright, E. W. \& Pearl, D. K. 1983. Time of conscious intention to act in relation to onset of cerebral activities (readiness potential): the unconscious initiation of a freely voluntary act. Brain, 106: 623-642.

Mele, A. R. 1992. Springs of Action. Oxford: Oxford University Press.

Mele, A. R. 2003. Motivation and Agency. Oxford: Oxford University Press.

Milner, A. D., and Goodale, M. A. 1995. The Visual Brain in Action. Oxford: Oxford University Press.

Nisbett, R. E. \& Wilson, T. D. 1977. Telling more than we can know: Verbal reports on mental processes. Psychological Review, 84: 231-259.

Pacherie, E. 2000. The content of intentions. Mind \& Language, 15, 4: 400-432.

Pacherie, E. 2003. La dynamique des intentions. Dialogue, XLII: 447-480.

Pisella, L., Arzi, M. \& Rossetti, Y. 1998. The timing of color and location processing in the motor context. Experimental Brain Research, 121: 270-276.

Pockett, S. 2004. Does consciousness cause behaviour? Journal of Consciousness Studies, 11, 2: $23-40$.

Rossetti, Y. \& Revonsuo, A. (eds) 2000. Beyond Dissociation - Interaction between dissociated implicit and explicit processing. Amsterdam/Philadelphia: John Benjamins Publishing Company.

Searle, J. 1983. Intentionality. Cambridge: Cambridge University Press.

Shallice, T. 1988. From neuropsychology to mental structure. Cambridge: Cambridge University Press.

Slachewsky, A., Pillon, B., Fourneret, P. Pradat-Diehl, Jeannerod, M. \& Dubois, B. 2001: Preserved adjustment but impaired awareness in a sensory-motor conflict following prefrontal lesions. Journal of Cognitive Neuroscience, 13: 332-340. 
Tucker, M. \& Ellis, R. 1998. On the relations between seen objects and components of potential actions. Journal of Experimental Psychology: Human Perception and Performance, 24: 830-846.

Wakefield, J. \& Dreyfus, H. 1991. Intentionality and the phenomenology of action. In E. Lepore \& R. Van Gulick (eds), John Searle and his critics. Cambridge, MA: Blackwell, pp. 259-270.

Wegner, D. M. \& Wheatley, T. 1999. Apparent mental causation. Sources of the experience of will. American Psychology, 54: 480-92.

Wegner, D. M. 2002. The illusion of conscious will. Cambridge, MA: MIT Press.

Wegner, D. M. 2003. The mind's self-portrait. Annals of the New-York Academy of Sciences, 1001: 1-14.

Wolpert, D. M. \& Ghahramani, Z. 2000. Computational principles of movement neuroscience. Nature Neuroscience Supplement, 3: 1212-1217.

Wolpert, D. M. 1997. Computational approaches to motor control. Trends in Cognitive Sciences, 1, 6: 209-216. 